\title{
Ylanders \\ State of the Art
}

\section{Inventory report}

on the possibility to update the ESAS database for the North Sea

Lien Reyserhove, Nicolas Vanermen, Peter Desmet, Tanja Milotic, Ruben Fijn, Nele Markones, Eric Stienen 


\section{Authors:

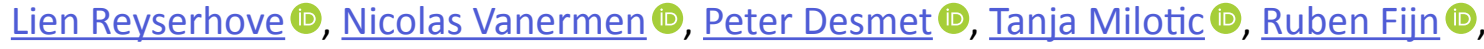

Nele Markones, Eric Stienen (1)

Research Institute for Nature and Forest (INBO)

\section{Reviewers:}

Dimitri Brosens, Marc Pollet

The Research Institute for Nature and Forest (INBO) is an independent research institute of the Flemish government. Through applied scientific research, open data and knowledge, integration and disclosure, it underpins and evaluates biodiversity policy and management.

\section{Location:}

INBO vestiging Herman Teirlinck

Havenlaan 88, 1000 Brussel

www.inbo.be

\section{e-mail:}

lien.reyserhove@inbo.be

\section{Way of quoting:}

Reyserhove L., Vanermen N., Desmet P., Milotic T., Fijn R., Markones N., Stienen E. (2021). Inventory report on the possibility to update the ESAS database for the North Sea. Reports of the Research Institute for Nature and Forest (42). Research Institute for Nature and Forest, Brussels. http://doi.org/10.21436/inbor.48142476

$D / 2021 / 3241 / 271$

Reports of the Research Institute for Nature and Forest (42)

ISSN: 1782-9054

\section{Responsible publisher:}

Maurice Hoffmann

\section{Cover photograph:}

Soaring Northern Fulmar roaming the North Sea (March 2019)

(credits: Nicolas Vanermen)

This research was carried out :

Rijkswaterstaat WVL, case number 31156322 


\section{INVENTORY REPORT ON THE POSSIBILITY TO UPDATE THE ESAS DATABASE FOR THE NORTH SEA}

Lien Reyserhove, Nicolas Vanermen, Peter Desmet, Tanja Milotic, Ruben Fijn, Nele Markones, Eric Stienen

http://doi.org/10.21436/inbor.48142476 


\section{Abstract}

This inventory report presents the results of the questionnaire set up to identify the existing 'seabirds at sea' (SAS) programmes collected in the OSPAR and HELCOM areas. For each country and SAS programme, we discuss the specific content and the potential constraints for future integration in the central ESAS database. We can conclude that data quality aspects (language use, update frequency, data format) allow for future migration. Only $8 \%$ of the respondents indicated to have financial constraints for sharing data, although one third indicated not to know. The legal aspects to the mobilization are considered to be the largest hindrance: almost half of the respondents indicated to have legal objections for sharing monitoring data. These results were discussed in a joint workshop and led to the conclusion that a joint international effort is essential to work towards a central ESAS database, which will automatically benefit the monitoring and research of seabirds in the North Sea. 


\section{Recommendations for management and/or policy}

This report is an important step towards an improved monitoring and research in the North Sea. Joint international effort is essential, and will allow for:

- better status assessments and trend analysis reporting,

- Environmental Impact Assessments (EIA) for marine industries,

- vulnerability and habitat suitability mapping,

- marine spatial planning and the designation of Marine Protected Areas,

- the identifications of management needs for internationally protected species,

- filling in knowledge gaps on seabird ecology.

Further involvement of each country is key. We therefore recommend to:

- install a network of delegates, with one or two representatives from each country who are involved in marine monitoring,

- approve a data sharing agreement on the details and level of public availability, which will enable a smooth data exchange,

- coordinate this network by a central steering committee, to facilitate a smooth and continuous transition of data to the database,

- make the ESAS methodology and standards as mandatory as possible in each country,

- focus on national and international survey scheme data and not too much on data from private companies 


\section{Table of contents}

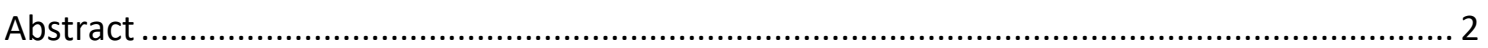

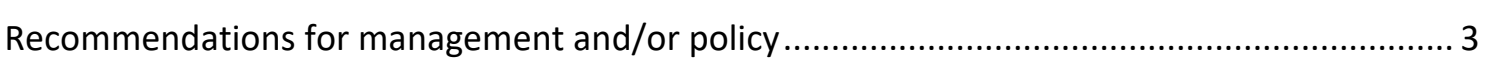

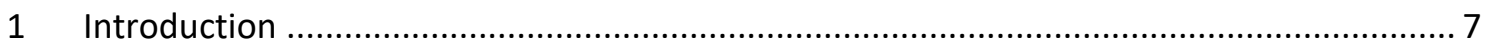

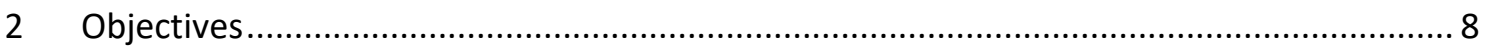

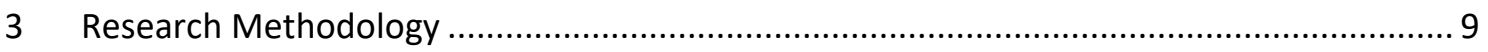

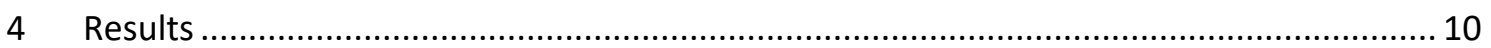

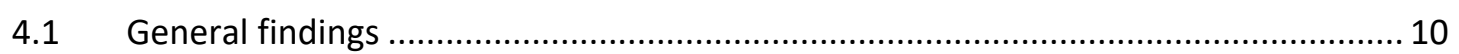

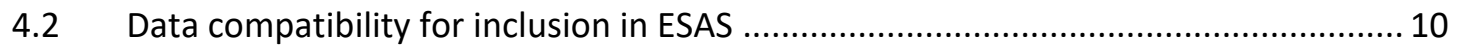

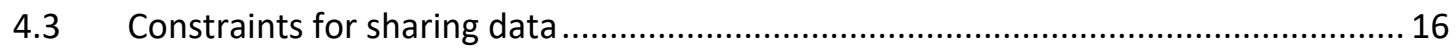

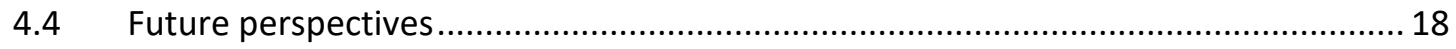

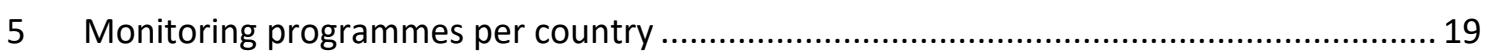

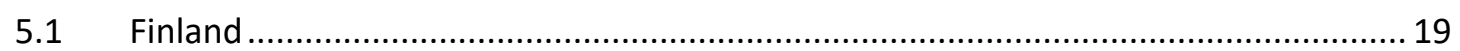

5.1.1 National offshore seabird programme (FIN-SYKE) …….................................. 19

5.1.2 The Archipelago Bird Census Monitoring (FIN-MNH) ..................................... 19

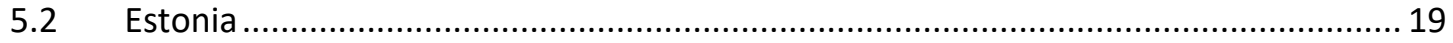

5.2.1 Aerial survey of seabirds in Estonian waters (EST-EMU) ..................................... 19

5.2.2 Monitoring by BirdLife Estonia (EST-EOS) ......................................................... 20

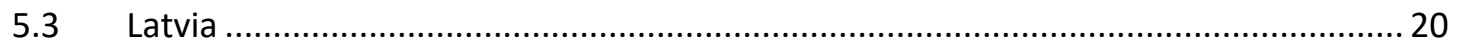

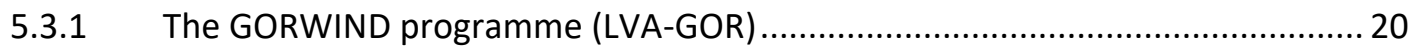

5.3.2 The Baltic MPAs programme (LVA-LIFE05) ......................................................... 20

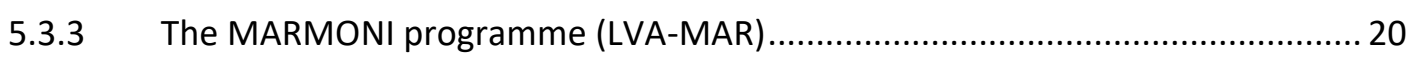

5.3.4 Survey on wintering Seabirds at Sea (LVA-WWAS) ........................................... 21

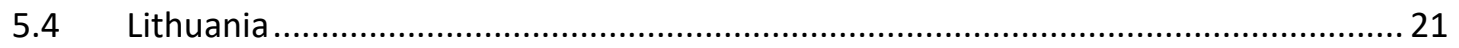

5.4.1 LIFE Marine Special Protection Area (SPA) project (LTU) ................................... 21

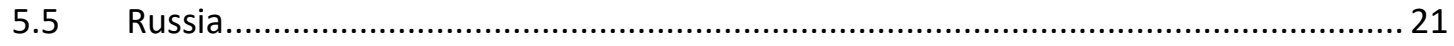

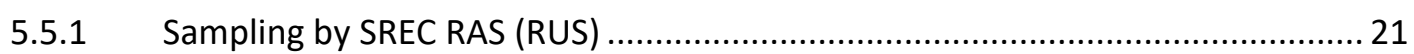

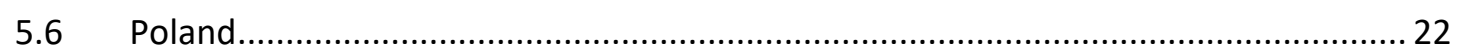

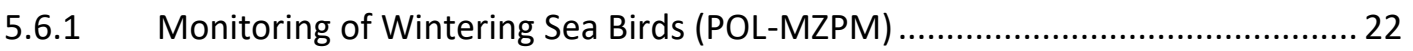

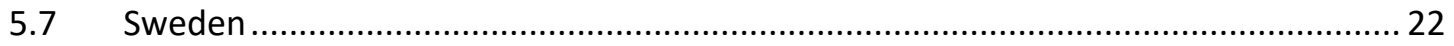

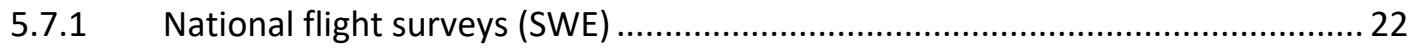

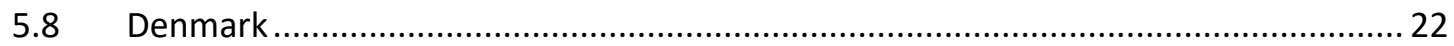

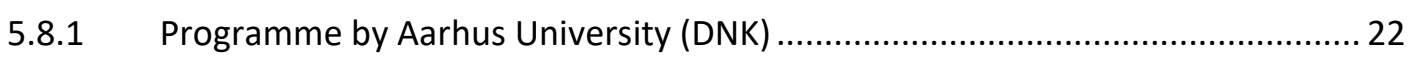

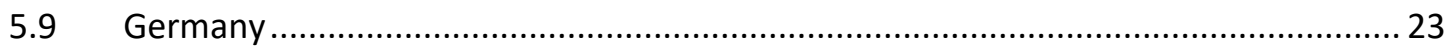

5.9.1 Monitoring by the Federal Maritime and Hydrographic Agency (DEU-BSH) ...... 23

5.9.2 The German Marine Biodiversity Monitoring programme (DEU-GMBM) ........... 23 
5.9.3 Offshore Seabird Monitoring in the Schleswig-Holstein coastal sea (DEU-OSMS) 23

5.9.4 The German Seabirds at Sea programme (DEU-SAS) ....................................... 24

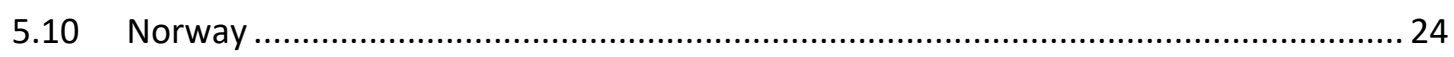

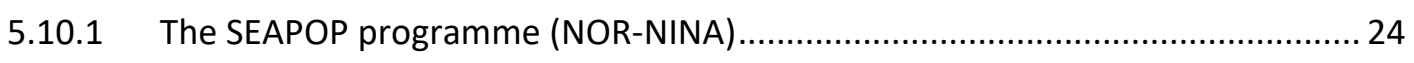

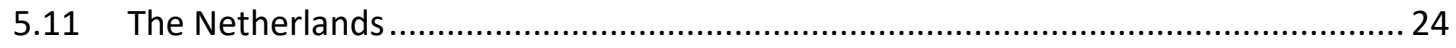

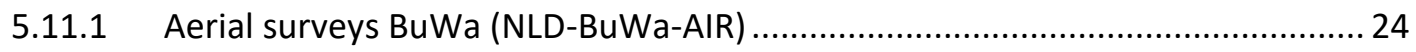

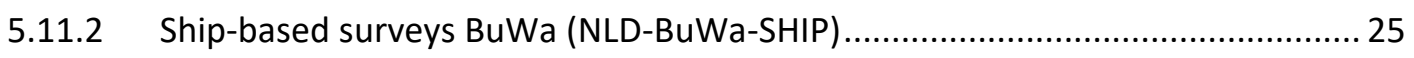

5.11.3 Monitoring Waterstaatkundige Toestand des Lands (MWTL) programme (NLMWTL) 25

5.11.4 Programme by Royal Netherlands Institute for Sea Research (NLD-NIOZ)......... 25

5.11.5 Programme by Wageningen Marine Research (NLD-WUR) ............................... 25

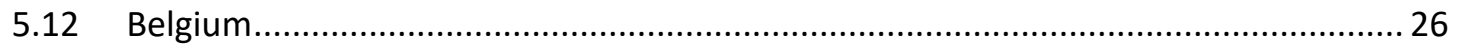

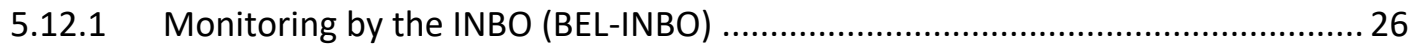

5.12.2 Monitoring by the MUMM (BEL-RBINS) ...................................................... 26

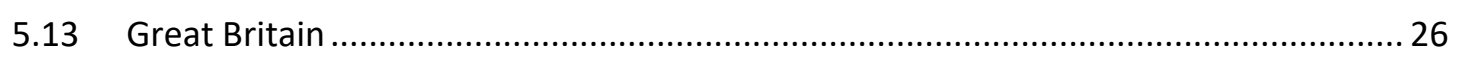

5.13.1 HiDef Aerial Surveying Limited (GBR-HIDEF) ................................................ 26

5.13.2 British Seabirds at Sea programme (GBR-JNCC) …........................................ 27

5.13.3 Sheringham Shoal Offshore Wind Farm programme (GBR-OWF) ...................... 27

5.13.4 Seagreen Firth of Forth Zone programme (GBR-SFF) ..................................... 27

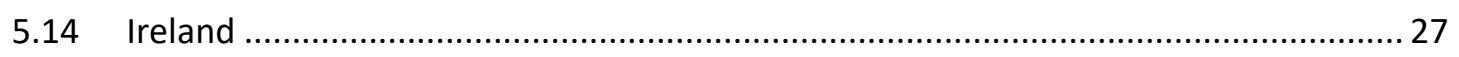

5.14.1 Monitoring programme led by National Parks and Wildlife Service (IRL-NPWS-1

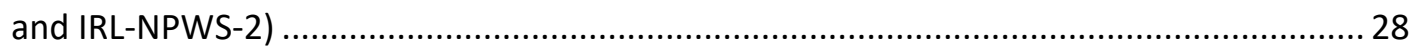

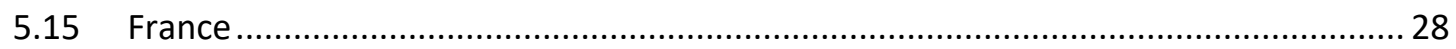

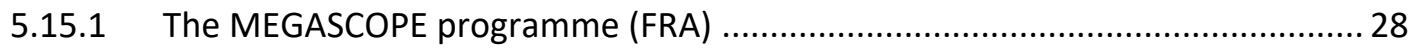

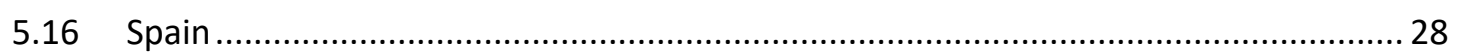

5.16.1 Seabird and cetacean monitoring programmes (ESP-AV3) ................................ 28

5.16.2 The JUVENA and BIOMAN programmes (ESP-JUV and ESP-BIO) .......................29

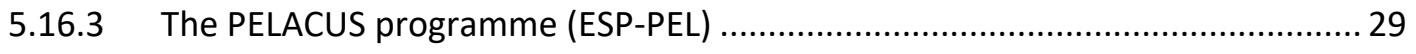

5.16.4 The ECOCADIZ programme (ESP-UCA) ……….............................................. 29

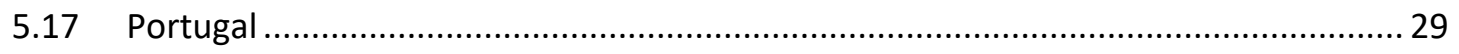

5.17.1 Portuguese Seabirds at Sea programme (PRT) ……......................................... 29

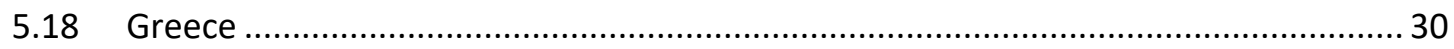

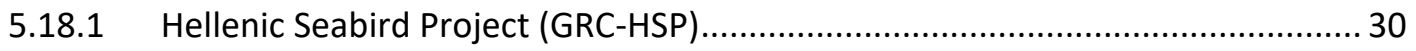

5.18.2 Past LIFE projects (GRC-LIFE96, GRC-LIFE03, GRC-LIFE07) ................................ 30

5.18.3 EU MSFD programme for Greece (GRC-MSFD) ............................................. 30

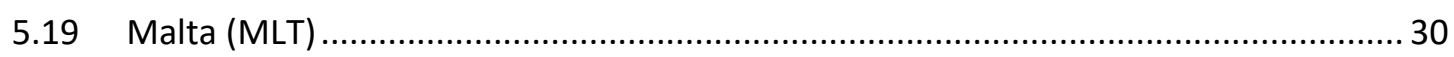




\section{INTRODUCTION}

A general lack of detailed quantitative knowledge on seabird distribution at sea was identified in the late 1970s. To share knowledge between seabird researchers, the European Seabirds at Sea (ESAS) database was established in 1991 as a collaboration between individuals and institutes who had collected data on the distribution of seabirds and marine mammals in north-west European offshore areas. In this database, distribution data of seabirds at sea (SAS data) and marine mammals were regularly added for over 25 years. The data were collected according to a standardised methodology, mostly during ship-based surveys in the North Sea basin. The most recent version of the ESAS database contains over two million records collected during ship-based and aerial surveys since 1979. The shared ESAS database has been managed by the Joint Nature Conservation Committee (JNCC) on behalf of the ESAS coordinating group. The JNCC is currently presenting distributional data of Seabirds at Sea (SAS) through the online Ocean Biogeographic Information System (OBIS) Seamap project (https://seamap.env.duke.edu/dataset/427). The OBIS database currently holds a subset of the ESAS database from the years ca. 1979 to ca. 2000. In addition, the Joint OSPAR/HELCOM/ICES Working Group on Seabirds (JWGBIRD) has plans to relocate the hosting and maintenance of the ESAS database to the International Council for the Exploration of the Sea (ICES) Data Centre and to be managed by a subgroup from JWGBIRD.

Unfortunately, the ESAS database has not been updated in the last decade, despite the fact that SAS surveys were continued to be carried out (ship-based counts as well as aerial surveys) by many different organisations. In the current project, "Inventory report on revitalizing the ESAS-database for the North Sea", issued by Rijkswaterstaat (RWS, the Netherlands) an update of the existing ESAS database with recent data is prepared as well as the migration of the database from the JNCC to the ICES Data Centre.

In Work package 1, the possibility to update the ESAS database with recent data is explored. This relies on knowing the extent of the current ESAS database (version 5) and more importantly identifying data sources holding recent data of ESAS partners that have not yet been added to the database as well as survey programmes that are not yet included in ESAS at all. In order to make an inventory of existing data sources, a questionnaire was sent out to the JWGBIRD consortium and additional researchers engaged in SAS research. The questionnaire was designed to identify the diverse sources of SAS data in Europe, in addition to the datasets that have previously been identified by the JWGBIRD consortium, and to investigate which datasets and monitoring programmes are suitable for inclusion in the ESAS database at a later stage. 


\section{OBJECTIVES}

This report includes the results of the inventory, and we will discuss for each country and dataset

- whether the data quality would allow for inclusion in the ESAS database and what problems are expected

- the specific content and whether marine mammal counts have been incorporated

- the financial and legal objections for integration in the ESAS database and an estimate of the costs of transforming the datasets into the ESAS data model. 


\section{RESEARCH METHODOLOGY}

The first version of the questionnaire was drafted by the Research Institute of Nature and Forest (INBO). This version was reviewed by the ESAS partners by the first half of June 2020 and was then distributed to Rijkswaterstaat (RWS) for further commenting. The final version of the questionnaire (https://github.com/inbo/esas-revitalize/tree/master/references) for distribution consisted of four main sections:

1. Monitoring programme information: general questions to provide more context

2. Scope and methodology: questions related to geographic scope, taxonomic scope, sampling platform as well as the sampling method, time of year, sampling interval and additional information

3. Data: identification of multiple data quality aspects such as number of species occurrences, data storage, language use, frequency of data import and inclusion in the current ESAS v5 database

4. Sharing data with ESAS: interest for sharing data with ESAS, as well as legal and financial constraints

A monitoring programme was defined as one or more seabirds at sea surveys with the same purpose, for instance "monitoring the numbers and distribution of seabirds in the Belgian part of the North Sea", "annual Ecosystem Survey in the Barents Sea" or "volunteer-based survey of seabirds and marine mammals using vessels of opportunity". The respondents were asked to fill out one questionnaire per monitoring programme.

By early July 2020, the questionnaire was officially distributed among the various potential data providers, which consist of the Joint ICES/OSPAR/HELCOM Working Group on Birds (JWGBIRD) consortium members, supplemented by additional researchers and institutes proposed by INBO, Bureau Waardenburg (BUWA), Forschungs- und Technologiezentrum Westküste (FTZ) and the project funder RWS, including potential data providers for the North Sea, Baltic Sea and Irish Sea. The deadline for submission was set in the middle of August. After expiry of the deadline, three consecutive reminders were sent to the contacts that did not respond. At the end of September, the questionnaire was closed and all collected answers were used in this inventory report. A detailed overview of the questionnaire can be found in the GitHub repository that was set up for this project (https://github.com/inbo/esasrevitalize). Before uploading the data, all email addresses were removed. The results of the questionnaire were analyzed in Rstudio (Rstudio Team 2020) ( $R$ script for conducting the analysis: https://github.com/inbo/esas-revitalize/tree/master/src). This report first includes a general discussion about the obtained results, followed by a detailed description of each dataset grouped by their country of origin. 


\section{RESULTS}

\subsection{GENERALFINDINGS}

Our questionnaire identified 48 monitoring programmes (one monitoring programme = one dataset in this text), associated with 34 organizations. Two organizations, Natural Power (Ireland, one programme) and the Dansk Marine Observers ApS (Denmark, one programme) did not share the requested information at the present time. Additionally, the Institute of Geography (Russian Federation, one programme) and the Bangor University (United Kingdom, one programme) indicated not to hold SAS data. This resulted in a total of 30 organizations involved in 44 SAS programmes successfully completing the questionnaire (Figure 1, Table 1). The overall purpose of these programmes is to monitor abundance and distribution of birds and marine mammal biodiversity on a regular basis, with some programmes specifically focusing on the impact of offshore wind farms, fisheries or ports.

\subsection{DATA COMPATIBILITY FOR INCLUSION IN ESAS}

All five OSPAR regions (https://www.ospar.org/convention/the-north-east-atlantic) are covered by the identified programmes, of which almost half of the programmes include the greater North Sea (OSPAR Region II) ( $n=19,43 \%$ ) (Table 2). The HELCOM areas (https://en.wikipedia.org/wiki/HELCOM) are covered by 14 datasets (31\%). All programmes include birds into their surveys, but $50 \%(n=22)$ of them also focus on the monitoring of marine mammals. The monitoring programmes vary markedly with respect to dataset size, temporal scope, and observation platform.

Table 1 Overview of the 44 SAS monitoring programmes collected by the questionnaire, with the programme ID (generated), country, organization of respondent and programme name.

\begin{tabular}{|c|c|c|c|}
\hline $\begin{array}{l}\text { Programme } \\
\text { ID }\end{array}$ & Country & Organization & Programme name/acronym \\
\hline FIN-SYKE & Finland & $\begin{array}{l}\text { Finnish Environment } \\
\text { Institute (SYKE) }\end{array}$ & $\begin{array}{l}\text { National offshore seabird monitoring } \\
\text { programme on wintering birds }\end{array}$ \\
\hline FIN-MNH & Finland & $\begin{array}{l}\text { Metsähallitus Nature and } \\
\text { Heritage }\end{array}$ & Archipelago Bird Census Monitoring \\
\hline EST-EMU & Estonia & $\begin{array}{l}\text { Estonian University of Life } \\
\text { Sciences (EMU) }\end{array}$ & $\begin{array}{l}\text { Aerial survey of seabirds in Estonian } \\
\text { waters }\end{array}$ \\
\hline EST-EOS & Estonia & BirdLife Estonia (EOS) & \\
\hline LVA-GOR & Latvia & $\begin{array}{l}\text { Latvian Ornithological } \\
\text { Society (LOB) }\end{array}$ & $\begin{array}{l}\text { The Gulf of Riga as a Resource for } \\
\text { Wind Energy (GORWIND) }\end{array}$ \\
\hline LVA-LIFE05 & Latvia & $\begin{array}{l}\text { Latvian Ornithological } \\
\text { Society (LOB) }\end{array}$ & LIFE project (LIFE05 NAT/LV/000100) \\
\hline LVA-MAR & Latvia & $\begin{array}{l}\text { Latvian Ornithological } \\
\text { Society (LOB) }\end{array}$ & MARMONI \\
\hline LVA-WWAS & Latvia & $\begin{array}{l}\text { Latvian Ornithological } \\
\text { Society (LOB) }\end{array}$ & Survey of wintering waterbirds at sea \\
\hline
\end{tabular}




\begin{tabular}{|c|c|c|c|}
\hline $\begin{array}{l}\text { Programme } \\
\text { ID }\end{array}$ & Country & Organization & Programme name/acronym \\
\hline LTU & Lithuania & Nature Research Centre (NRC) & LIFE Marine SPAs \\
\hline RUS & $\begin{array}{l}\text { Russian } \\
\text { Federation }\end{array}$ & $\begin{array}{l}\text { Scientific Research Center for } \\
\text { Ecological Safety (SRCES RAS) }\end{array}$ & \\
\hline POL-MZPM & Poland & $\begin{array}{l}\text { Chief Inspector of Environmental } \\
\text { Protection (GIOS) }\end{array}$ & $\begin{array}{l}\text { Monitoring of Wintering Sea } \\
\text { Birds (MZPM) }\end{array}$ \\
\hline SWE & Sweden & Lund university & \\
\hline DNK & Denmark & Aarhus University (AU) & \\
\hline DEU-BSH & Germany & $\begin{array}{l}\text { Federal Maritime and } \\
\text { Hydrographic Agency (BSH) }\end{array}$ & \\
\hline DEU-GMBM & Germany & $\begin{array}{l}\text { Kiel University, Research and } \\
\text { Technology Centre Westcoast } \\
\text { (FTZ) }\end{array}$ & $\begin{array}{l}\text { German Marine Biodiversity } \\
\text { Monitoring }\end{array}$ \\
\hline DEU-OSMS & Germany & $\begin{array}{l}\text { Kiel University, Research and } \\
\text { Technology Centre Westcoast } \\
\text { (FTZ) }\end{array}$ & $\begin{array}{l}\text { Offshore Seabird Monitoring in } \\
\text { the Schleswig-Holstein coastal } \\
\text { sea, North Sea }\end{array}$ \\
\hline DEU-SAS & Germany & $\begin{array}{l}\text { Kiel University, Research and } \\
\text { Technology Centre Westcoast } \\
\text { (FTZ) }\end{array}$ & $\begin{array}{l}\text { German Seabirds at Sea } \\
\text { programme (SAS) }\end{array}$ \\
\hline NOR-NINA & Norway & $\begin{array}{l}\text { Norwegian Institute for Nature } \\
\text { Research (NINA) }\end{array}$ & Seabird populations (SEAPOP) \\
\hline $\begin{array}{l}\text { NLD-BuWa- } \\
\text { AIR }\end{array}$ & Netherlands & Bureau Waardenburg (BuWa) & \\
\hline $\begin{array}{l}\text { NLD-BuWa- } \\
\text { SHIP }\end{array}$ & Netherlands & Bureau Waardenburg (BuWa) & \\
\hline NLD-MWTL & Netherlands & Bureau Waardenburg (BuWa) & $\begin{array}{l}\text { Monitoring van de } \\
\text { Waterstaatkundige Toestand } \\
\text { des Lands (MWTL), zeevogels }\end{array}$ \\
\hline NLD-NIOZ & Netherlands & $\begin{array}{l}\text { Royal Netherlands Institute for } \\
\text { Sea Research (NIOZ) }\end{array}$ & \\
\hline NLD-WUR & Netherlands & $\begin{array}{l}\text { Wageningen Marine Research } \\
\text { (WUR) }\end{array}$ & \\
\hline BEL-INBO & Belgium & $\begin{array}{l}\text { Research Institute for Nature and } \\
\text { Forest (INBO) }\end{array}$ & \\
\hline BEL-RBINS & Belgium & $\begin{array}{l}\text { Royal Belgian Institute for } \\
\text { Natural Sciences (RBINS) }\end{array}$ & \\
\hline GBR-HIDEF & $\begin{array}{l}\text { United } \\
\text { Kingdom }\end{array}$ & $\begin{array}{l}\text { HiDef Aerial Surveying Limited } \\
\text { (HiDef) }\end{array}$ & $\begin{array}{l}\text { Multiple post-consent and } \\
\text { Special Protection Area (SPA) } \\
\text { monitoring projects }\end{array}$ \\
\hline GBR-JNCC & $\begin{array}{l}\text { United } \\
\text { Kingdom }\end{array}$ & $\begin{array}{l}\text { Joint Nature Conservation } \\
\text { Committe (JNCC) }\end{array}$ & $\begin{array}{l}\text { Brittish Seabirds at Sea } \\
\text { programme (SAS) }\end{array}$ \\
\hline
\end{tabular}




\begin{tabular}{|c|c|c|c|}
\hline $\begin{array}{l}\text { Programme } \\
\text { ID }\end{array}$ & Country & Organization & Programme name/acronym \\
\hline GBR-OWF & $\begin{array}{l}\text { United } \\
\text { Kingdom }\end{array}$ & Ecological Consultancy (ECON) & $\begin{array}{l}\text { Sheringham Shoal Offshore } \\
\text { Wind Farm (OWF) }\end{array}$ \\
\hline GBR-SFF & $\begin{array}{l}\text { United } \\
\text { Kingdom }\end{array}$ & Ecological Consultancy (ECON) & Seagreen Firth of Forth zone \\
\hline IRL-NPWS-1 & Ireland & $\begin{array}{l}\text { National Parks and Wildlife } \\
\text { Service (NPWS) }\end{array}$ & \\
\hline IRL-NPWS-2 & Ireland & $\begin{array}{l}\text { National Parks and Wildlife } \\
\text { Service (NPWS) }\end{array}$ & ObSERVE and others \\
\hline FRA & France & La Rochelle University & MEGASCOPE \\
\hline ESP-AV3 & Spain & $\begin{array}{l}\text { Instituto Español de } \\
\text { Oceanografía (IEO) }\end{array}$ & IEO-AV3 \\
\hline ESP-BIO & Spain & AZTI Tecnalia (AZTI) & BIOMAN \\
\hline ESP-JUV & Spain & AZTI Tecnalia (AZTI) & JUVENA \\
\hline ESP-PEL & Spain & $\begin{array}{l}\text { Instituto Español de } \\
\text { Oceanografía (IEO) }\end{array}$ & PELACUS \\
\hline ESP-UCA & Spain & University of Cadiz (UCA) & ECOCADIZ \\
\hline PRT & Portugal & $\begin{array}{l}\text { Society for the Study of Birds } \\
\text { (SPEA) }\end{array}$ & $\begin{array}{l}\text { European Seabirds at Sea } \\
\text { (ESAS) }\end{array}$ \\
\hline GRC-HSP & Greece & $\begin{array}{l}\text { Hellenic Ornithological Society } \\
\text { (HOS) / BirdLife Greece }\end{array}$ & Hellenic Seabird Project \\
\hline GRC-LIFE03 & Greece & $\begin{array}{l}\text { Hellenic Ornithological Society } \\
\text { (HOS) / BirdLife Greece }\end{array}$ & $\begin{array}{l}\text { LIFE project (LIFE03 } \\
\text { NAT/GR/000091) }\end{array}$ \\
\hline GRC-LIFE07 & Greece & $\begin{array}{l}\text { Hellenic Ornithological Society } \\
\text { (HOS) / BirdLife Greece }\end{array}$ & $\begin{array}{l}\text { LIFE project (LIFE07 } \\
\text { NAT/GR/000285) }\end{array}$ \\
\hline GRC-LIFE96 & Greece & $\begin{array}{l}\text { Hellenic Ornithological Society } \\
\text { (HOS) }\end{array}$ & $\begin{array}{l}\text { LIFE project (LIFE96 } \\
\text { NAT/GR/003221) }\end{array}$ \\
\hline GRC-MSFD & Greece & $\begin{array}{l}\text { Hellenic Ornithological Society } \\
\text { (HOS) / BirdLife Greece }\end{array}$ & $\begin{array}{l}\text { EU Marine Strategy } \\
\text { Framework Directive for } \\
\text { Greece }\end{array}$ \\
\hline MLT & Malta & $\begin{array}{l}\text { Hellenic Ornithological Society } \\
\text { (HOS) / BirdLife Greece }\end{array}$ & $\begin{array}{l}\text { LIFE project (LIFE19 } \\
\text { NAT/MT/000982) }\end{array}$ \\
\hline
\end{tabular}


Table 2 Programme specifics: temporal scope (blue: active programme), number of occurrences, geographical focus: OSPAR region (I: Arctic waters, II: Greater North Sea, III: Greater North Sea, IV: Bay of Biscay and Iberian Coast, empty if not applicable) or Baltic Sea (yes if sampling in Baltic Sea, empty if not applicable), Marine mammals (yes if programme includes marine mammals monitoring), and platform: Plane (yes if aerial observations) and Ship (yes if observations by boat).

\begin{tabular}{|c|c|c|c|c|c|c|c|}
\hline Programme ID & $\begin{array}{l}\text { Temporal } \\
\text { scope }\end{array}$ & $\begin{array}{l}\text { Nr of } \\
\text { occurrences }\end{array}$ & $\begin{array}{l}\text { OSPAR } \\
\text { region }\end{array}$ & $\begin{array}{l}\text { Baltic } \\
\text { Sea }\end{array}$ & $\begin{array}{l}\text { Marine } \\
\text { mammals }\end{array}$ & Plane & Ship \\
\hline FIN-SYKE & 1996-now & $100 \mathrm{~K}-1 \mathrm{M}$ & & yes & & yes & yes \\
\hline FIN-MNH & 1980-now & $100 \mathrm{~K}-1 \mathrm{M}$ & & yes & & & yes \\
\hline EST-EMU & 2016-now & $10 \mathrm{~K}-100 \mathrm{~K}$ & & yes & & yes & \\
\hline EST-EOS & 2006-now & $10 \mathrm{~K}-100 \mathrm{~K}$ & & yes & & & yes \\
\hline LVA-GOR & 2011-2012 & $1-10 K$ & & yes & & yes & \\
\hline LVA-LIFE05 & 2005-2008 & & & yes & & & yes \\
\hline LVA-MAR & 2011-2014 & $10 \mathrm{~K}-100 \mathrm{~K}$ & & yes & & yes & yes \\
\hline LVA-WWAS & 2016-now & $10 \mathrm{~K}-100 \mathrm{~K}$ & & yes & & yes & \\
\hline LTU & 2006-2008 & $10 \mathrm{~K}-100 \mathrm{~K}$ & & yes & & & yes \\
\hline RUS & 2018-2018 & $1-10 K$ & & yes & & yes & \\
\hline POL-MZPM & 2011-now & $100 \mathrm{~K}-1 \mathrm{M}$ & & yes & & & yes \\
\hline SWE & 2004-now & $10 \mathrm{~K}-100 \mathrm{~K}$ & II & yes & & yes & \\
\hline DNK & 2004-now & $100 \mathrm{~K}-1 \mathrm{M}$ & II & yes & & yes & \\
\hline DEU-BSH & 2000-now & & II & yes & yes & yes & yes \\
\hline DEU-GMBM & 2008-now & & II & & yes & yes & yes \\
\hline DEU-OSMS & 2004-now & & II & & & yes & yes \\
\hline DEU-SAS & 1990-now & & II & & yes & yes & yes \\
\hline NOR-NINA & 2004-now & $>1 \mathrm{M}$ & I & & yes & & yes \\
\hline NLD-BuWa-AIR & 2004-now & $100 \mathrm{~K}-1 \mathrm{M}$ & II & & yes & yes & \\
\hline $\begin{array}{l}\text { NLD-BuWa- } \\
\text { SHIP }\end{array}$ & 2004-now & $10 \mathrm{~K}-100 \mathrm{~K}$ & II & & yes & & yes \\
\hline NLD-MWTL & 1991-now & $100 \mathrm{~K}-1 \mathrm{M}$ & II & & yes & yes & \\
\hline NLD-NIOZ & 1985-now & $>1 \mathrm{M}$ & I,II,IV,V & & & & yes \\
\hline NLD-WUR & 1980-now & & I, II, III, IV & & yes & & yes \\
\hline BEL-INBO & 1992-now & $100 \mathrm{~K}-1 \mathrm{M}$ & II & & yes & & yes \\
\hline BEL-RBINS & 2008-now & $1-10 K$ & II & & yes & yes & \\
\hline GBR-HIDEF & 2011-now & $>1 \mathrm{M}$ & II,III & & yes & yes & \\
\hline GBR-JNCC & 1980-now & & II,III & & yes & yes & yes \\
\hline GBR-OWF & 2004-2016 & $10 \mathrm{~K}-100 \mathrm{~K}$ & II & & yes & & yes \\
\hline
\end{tabular}




\begin{tabular}{|c|c|c|c|c|c|c|c|}
\hline Programme ID & $\begin{array}{l}\text { Temporal } \\
\text { scope }\end{array}$ & $\begin{array}{l}\text { Nr of } \\
\text { occurrences }\end{array}$ & $\begin{array}{l}\text { OSPAR } \\
\text { region }\end{array}$ & $\begin{array}{l}\text { Baltic } \\
\text { Sea }\end{array}$ & $\begin{array}{l}\text { Marine } \\
\text { mammals }\end{array}$ & Plane & Ship \\
\hline GBR-SFF & 2009-now & $100 \mathrm{~K}-1 \mathrm{M}$ & II & & yes & & yes \\
\hline IRL-NPWS-1 & 2018-now & $1-10 K$ & III & & yes & & yes \\
\hline IRL-NPWS-2 & 2016-now & & II,III & & & yes & yes \\
\hline FRA & 2004-now & $10 \mathrm{~K}-100 \mathrm{~K}$ & II,III,IV & & yes & yes & yes \\
\hline ESP-AV3 & 2007-now & $10 \mathrm{~K}-100 \mathrm{~K}$ & IV & & yes & & yes \\
\hline ESP-BIO & 2016-now & $1-10 K$ & IV & & yes & & yes \\
\hline ESP-JUV & 2013-now & $1-10 K$ & IV & & yes & & yes \\
\hline ESP-PEL & 2007-now & $10 \mathrm{~K}-100 \mathrm{~K}$ & IV & & yes & & yes \\
\hline ESP-UCA & 2006-now & $1-10 \mathrm{~K}$ & IV & & yes & & yes \\
\hline PRT & 2005-now & $100 \mathrm{~K}-1 \mathrm{M}$ & IV,V & & yes & & yes \\
\hline GRC-HSP & 2013-now & $1-10 \mathrm{~K}$ & & & & & yes \\
\hline GRC-LIFE03 & 2004-2006 & $1-10 \mathrm{~K}$ & & & & & yes \\
\hline GRC-LIFE07 & 2009-2012 & $1-10 \mathrm{~K}$ & & & & & yes \\
\hline GRC-LIFE96 & $1992-2001$ & $1-10 K$ & & & yes & & yes \\
\hline GRC-MSFD & 2020-now & $1-10 \mathrm{~K}$ & & & & & yes \\
\hline MLT & 2020-now & $1-10 \mathrm{~K}$ & & & & & yes \\
\hline
\end{tabular}




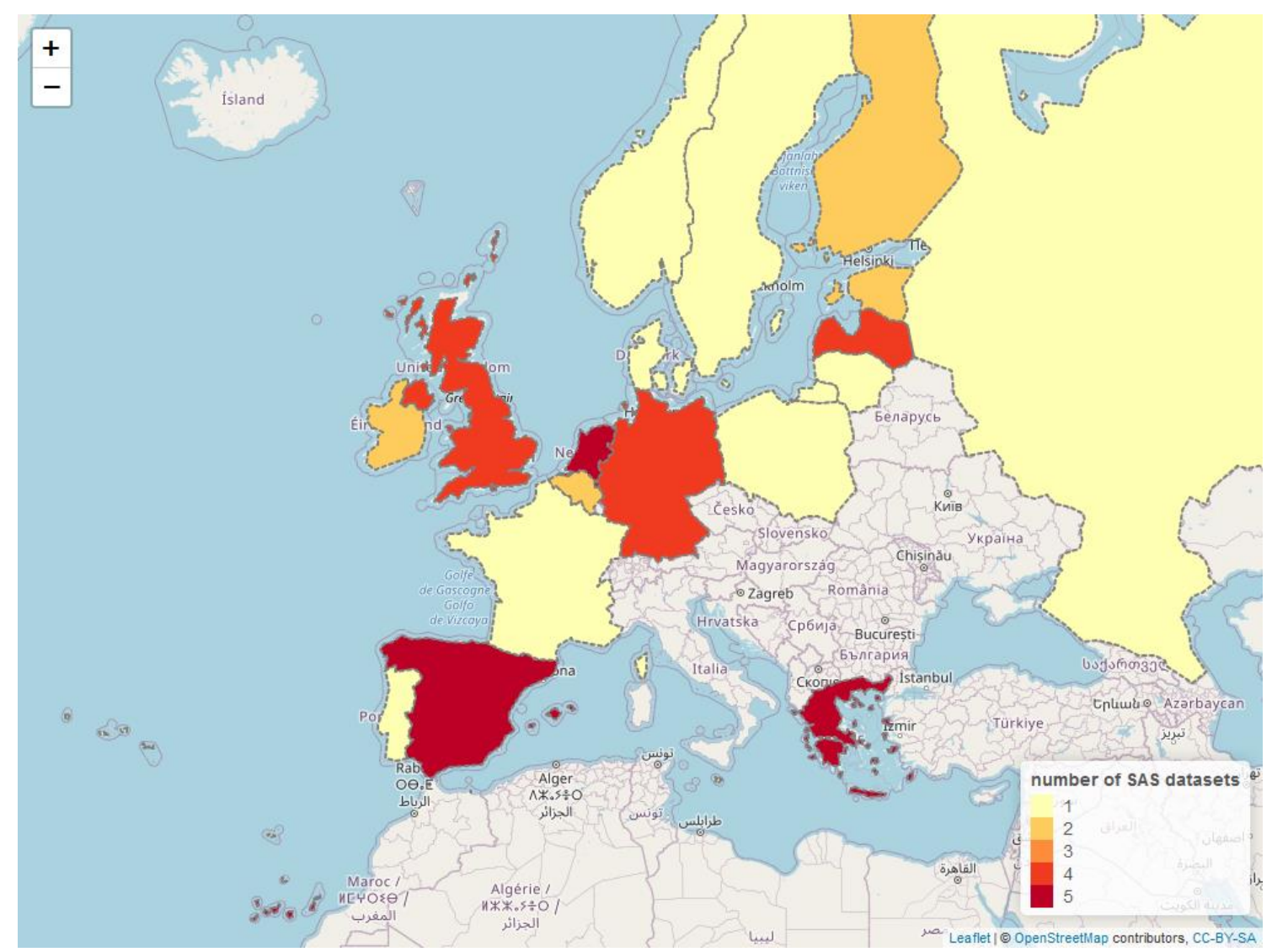

Figure 1 Map with number of SAS monitoring programmes per country. One (out of three) SAS programmes in Ireland and one (out of two) SAS programmes in Denmark are not included, as they were not allowed to share information.

We identified three main data quality aspects that could hinder the unification of the identified programmes into a single ESAS v6 database: language use, data update frequency and data storage. Most fields in the ESAS v5 database are encoded, except the remark field, which contains full text. Thus, different language use in these remark fields should not be a big problem. For each active programme, data updates into the local data management system takes place one year after field sampling at the latest, meaning that all active datasets are kept up to date. Some of the datasets are managed in a structured file such as a comma separated file $(11 \%)$ or Excel file $(52 \%)$, some are held in a relational database such as Microsoft Access (34\%), SQL or Postgres (22\%) or Paradox (11\%). Some datasets are stored as shapefiles (4\%) or in a GIS database (2\%) Most data are stored in multiple systems. We can conclude that there are no main issues with respect to language use, update frequency or data storage that could obstruct future integration into a single ESAS database.

Dataset content quality was assessed using two criteria: (1) current inclusion in the ESAS database and (2) sampling methodology. Programmes already or partially included in the ESAS database ( $n=10$ or $22 \%$ ) already use the correct protocol and are considered to be of sufficient quality (Table 3). Ship-based observations are considered to be of high quality if they are generated by using (1) distance estimation methods combined with (2) snapshot counts for flying birds. For aerial observations also, the method (both line or strip transects) should make use of distance sampling methods. Based on this definition, four of the five Spanish programmes (ESP-AV3, ESP-PEL, ESP-JUV and ESP-BIO) and the Lithuanian programme (LTU) were identified to potentially contain low quality data. These ship-based programmes did not 
use snapshot counts for flying birds as a methodology or did not use distance estimation. Two programmes, the Finnish National offshore seabird monitoring programme on wintering birds (FIN-SYKE) and the French MEGASCOPE programme (FRA) combine lower quality shipbased (no snapshot count for flying birds) data with higher quality aerial data. For the Finnish Archipelago Bird Census Monitoring (FIN-MNH) programme, no information on these specific sampling methodologies is available and as such, data quality could not be assessed.

\subsection{CONSTRAINTS FOR SHARING DATA}

Out of the 44 identified ESAS programmes, only three are fully integrated in the ESAS v5 database: the British Seabirds at Sea programme led by the Joint Nature Conservation Committee (GBR-JNCC), the SAS programme led by Wageningen Marine Research (NLD-WUR) and the "monitoring van de Waterstaatkundige Toestand des Lands (MWTL), zeevogels" programme carried out by Bureau Waardenburg (NLD-MWTL) and commissioned by Rijkswaterstaat. However, recent updates are missing for the GBR-JNCC and MWTL programmes. To date, almost half of the programmes have not yet been included in the database $(n=21,48 \%)$, eight of them are partially integrated $(18 \%)$ and for four datasets $(9 \%)$, integration has been planned.

A large proportion $(75 \%, n=33)$ of the respondents indicated to be interested in sharing their SAS data. None of the organizations was unwilling to share their data: the other $25 \%(n=11)$ indicated not to know if sharing their SAS data is allowed. The legal aspect will be the largest hurdle for sharing the data: almost half $(n=20)$ of the respondents indicated to have legal objections for sharing monitoring data. In most of these cases, the data is owned by third parties (private companies or commissioners) and thus mobilization towards a single ESAS database should be authorized first. Others indicated that the legal conditions for sharing data differ between subsets of the data and should thus be considered for each case separately. In this respect, it is important to note that the data sharing agreement imposed by ICES allows data providers to choose between public and restricted access for (subsets of) their share of the data. The data sharing agreement specifications will be clearly communicated among all potential and current data providers and owners.

Another obstacle is ownership and attribution: ownership flags need to be maintained and appropriately credited. For almost half $(48 \%, n=21)$ of the monitoring programmes, no financial constraints were identified, although $34 \%(n=15)$ indicated not to know. The remaining $8 \%$ indicated to have financial constraints for sharing the data, with costs estimated between 2.500 and 8.000 euro.

Table 3 Inclusion of programmes in the current ESAS v5 database, sharing interest with respect to future mobilization to ESAS v6 database and the financial and legal constraints for sharing.

\begin{tabular}{|l|l|l|l|l|}
\hline Programme ID & Inclusion ESAS DB & Sharing interest & financial constraints & legal constraints \\
\hline FIN-SYKE & Unknown & Yes & No & No \\
\hline FIN-MNH & No & Unknown & Unknown & Yes \\
\hline EST-EMU & Partially & Yes & Unknown & Yes \\
\hline EST-EOS & No & Yes & Unknown & Yes \\
\hline LVA-GOR & No & Yes & Yes & Unknown \\
\hline
\end{tabular}




\begin{tabular}{|c|c|c|c|c|}
\hline Programme ID & Inclusion ESAS DB & Sharing interest & financial constraints & legal constraints \\
\hline LVA-LIFE05 & Unknown & Yes & No & No \\
\hline LVA-MAR & No & Unknown & Unknown & Unknown \\
\hline LVA-WWAS & Planned & Yes & Unknown & Yes \\
\hline LTU & Unknown & Yes & No & No \\
\hline RUS & No & Unknown & No & No \\
\hline POL-MZPM & No & Yes & Unknown & Unknown \\
\hline SWE & Planned & Yes & Yes & Yes \\
\hline DNK & No & Unknown & Unknown & Unknown \\
\hline DEU-BSH & No & Unknown & Unknown & Yes \\
\hline DEU-GMBM & Partially & Yes & No & Yes \\
\hline DEU-OSMS & Partially & Unknown & No & Unknown \\
\hline DEU-SAS & Partially & Yes & No & Yes \\
\hline NOR-NINA & No & Yes & No & No \\
\hline NLD-BuWa-AIR & No & Yes & Yes & Yes \\
\hline NLD-BuWa-SHIP & Unknown & Yes & Yes & Yes \\
\hline NLD-MWTL & Planned & Yes & No & No \\
\hline NLD-NIOZ & Partially & Yes & No & Yes \\
\hline NLD-WUR & Yes & Yes & No & Yes \\
\hline BEL-INBO & Partially & Yes & No & Yes \\
\hline BEL-RBINS & No & Unknown & No & Yes \\
\hline GBR-HIDEF & No & Yes & No & Yes \\
\hline GBR-JNCC & Yes & Yes & No & No \\
\hline GBR-OWF & No & Unknown & Unknown & Unknown \\
\hline GBR-SFF & No & Unknown & Unknown & Unknown \\
\hline IRL-NPWS-1 & Partially & Yes & Unknown & Yes \\
\hline IRL-NPWS-2 & Unknown & Yes & Unknown & Unknown \\
\hline FRA & Unknown & Yes & No & Yes \\
\hline ESP-AV3 & No & Unknown & Unknown & Unknown \\
\hline ESP-BIO & No & Yes & Yes & Yes \\
\hline ESP-JUV & No & Yes & Yes & Yes \\
\hline ESP-PEL & No & Yes & Unknown & Unknown \\
\hline ESP-UCA & Planned & Unknown & Unknown & Yes \\
\hline
\end{tabular}




\begin{tabular}{|l|l|l|l|l|}
\hline Programme ID & Inclusion ESAS DB & Sharing interest & financial constraints & legal constraints \\
\hline PRT & Partially & Yes & No & No \\
\hline GRC-HSP & No & Yes & No & Unknown \\
\hline GRC-LIFE03 & Unknown & Yes & No & Unknown \\
\hline GRC-LIFE07 & Unknown & Yes & No & Unknown \\
\hline GRC-LIFE96 & Unknown & Yes & No & Unknown \\
\hline GRC-MSFD & No & Yes & Yes & Unknown \\
\hline MLT & No & Yes & Yes & Unknown \\
\hline
\end{tabular}

\subsection{FUTURE PERSPECTIVES}

On March $25^{\text {th }} 2021$, an ESAS database workshop was organized by RWS to:

- present the results outlined in this inventory report

- discuss on the potential use of an updated ESAS database

- explore the way forward

This workshop was attended by representatives from the United Kingdom, Belgium, the Netherlands, France and BirdLife International.

It was concluded that a joint international effort is essential to improve monitoring and research in the North Sea, with the HELCOM approach on joint seabird monitoring as the main example. This will benefit status assessments and trend analysis reporting, Environmental Impact Assessments (EIA) for marine industries, vulnerability and habitat suitability mapping, marine spatial planning and the designation of Marine Protected Areas, the identification of management needs for internationally protected species and filling in knowledge gaps on seabird ecology. For this, involvement of each country is key. The idea was launched to install a network of delegates, with one or two representatives from each country who are involved in marine monitoring. The setup of such a network could act as an incentive for uploading data to the central ESAS database. This network would preferably be coordinated by a central steering committee, to facilitate a smooth and continuous transition of data to the database. This would however require funding, so possibilities will be explored to apply for funding on a EU scale. The need for standardized monitoring was recognized. It was suggested to make the ESAS methodology and standards as mandatory as possible in each country. With respect to the migration of historical data to the ESAS database, it was further suggested to focus on national and international survey scheme data and not too much on data from private companies. 


\section{MONITORING PROGRAMMES PER COUNTRY}

The following section gives an overview of the specifics for each monitoring programme, grouped by country. For each monitoring programme, we discuss the specific goal, timeframe, geographical and taxonomic focus and dataset size (number of species occurrence records), complemented with information on the current integration in the ESAS v5 database and the potential financial and legal objections for integration in the updated ESAS v6 database. As discussed earlier in this report, data quality allows in almost all cases for inclusion in the ESAS database. When problems are expected with respect to data quality, we indicate this specifically in the text below.

\subsection{FINLAND}

Finland currently has two active seabird programmes: the National offshore seabird programme and the Archipelago Bird Census Monitoring.

\subsubsection{National offshore seabird programme (FIN-SYKE)}

The Finnish Environment Institute (SYKE) has been leading the national offshore seabird monitoring programme since 1996. The programme comprises aerial surveys (every four years) that cover the regularly ice-free areas during winter. Four monitoring routes in the Åland Sea and Archipelago Sea are annually covered by ship. Three of the routes have been covered yearly since 1996. The fourth route is placed in the middle of the Archipelago Sea along the ship. The programme focuses on birds only and generated between 100,000 and 1 million records. There's an interest to share the data, no legal or financial constraints for the mobilization were identified.

Contact person: Markku Mikkola-Roos

\subsubsection{The Archipelago Bird Census Monitoring (FIN-MNH)}

The Archipelago Bird Census Monitoring programme has been led by Metsähallitus Nature and Heritage since 1980 .The programme was set up to monitor the abundance of breeding birds on islands in Finnish archipelago and is ship-based. The programme generated between 100,000 and 1 million records which have not been included in the current ESAS database yet. It is unknown whether the data will be shared in the future or whether financial constraints obstruct the mobilization. The data can only be shared without point coordinates, e.g. in $50 \mathrm{~km}$ squares.

Contact person: Antti Below

\subsection{ESTONNIA}

Estonia is involved in two ongoing SAS programmes in the Baltic Sea.

\subsubsection{Aerial survey of seabirds in Estonian waters (EST-EMU)}

The Estonian University of Life Sciences (EMU) is currently performing aerial surveys on the winter distribution of seabirds in Estonian coastal waters. This survey started in 2016 and is 
scheduled once every four year. The dataset includes between 10,000 and 100,000 records, from which a part is included in the current ESAS v5 database. Although EMU is interested in sharing their SAS data, the legal conditions for the mobilizations of the data should be specified by the Environmental Board of Estonia.

Contact person: Leho Luigujõe

\subsubsection{Monitoring by BirdLife Estonia (EST-EOS)}

Year-round, ship-based counts have been performed in the Baltic Sea by BirdLife Estonia since 2006 , which generated between 10,000 and 100,000 records. These data are currently not available in the ESAS database, though BirdLife Estonia expressed to be willing to share their data. No financial constraints were specified. However, as other organizations are involved in the censuses, the sharing conditions would need to be negotiated with the owners on a caseby-case basis.

Contact person: Andrus Kuus

\subsection{LATVIA}

Latvia currently has one ongoing and two completed SAS programmes carried out by the Latvian Ornithological Society, with a specific focus on the Baltic Sea. None of these programmes are currently included in the ESAS v5 database.

\subsubsection{The GORWIND programme (LVA-GOR)}

The GORWIND project started in 2011 and lasted for one year. The project was set up to provide decision makers and potential developers of wind farms in the Gulf of Riga with reliable marine wind information from high resolution remote sensing data, coastal wind measurements and ensemble of regional climate models. Furthermore, information on habitat area for seals, wintering, migrating and breeding birds was collected. The database of the programme includes up to 10,000 records. The data owners are interested to share their data. Although financial constraints for the mobilization were identified, no specific costs were mentioned. Whether or not the legal aspect will be an issue is unknown.

Contact person: Ainars Aunins

\subsubsection{The Baltic MPAs programme (LVA-LIFE05)}

The LIFE project "Baltic MPAs - Marine protected areas in the Eastern Baltic Sea" (LIFE05 NAT/LV/000100, 2005-2008) aimed to contribute to the protection and sustainable use of marine biodiversity in the coastal and offshore waters of Estonia, Latvia and Lithuania. The sampling was ship-based and focused on birds only. There's an interest to share the data, no financial or legal constraints for mobilization were identified.

Contact person: Antra Stīpniece

\subsubsection{The MARMONI programme (LVA-MAR)}

The MARMONI project was set up in 2011 and was rolled out in four different countries: Latvia, Estonia, Sweden and Finland. The goal of this project was to monitor the state of marine biodiversity by developing indicators for monitoring and assessment of marine biodiversity, conservation status of species and habitats, as well as impacts of human activities 
in the Baltic Sea. The programme ended in 2014. Sampling was carried out by airplane and/or ship. The project generated between 10,000 and 100,000 records. No financial nor legal objections for the mobilization were specified.

Contact person: Ainars Aunins

\subsubsection{Survey on wintering Seabirds at Sea (LVA-WWAS)}

The Latvian Nature Conservation Agency is the national authority for organizing surveys on wintering seabirds in the Baltic Sea, Latvia. The surveys are carried out by subcontractors. So far, all actual aerial surveys have been carried out by the Latvian Ornithological Society. Since 2016, they have been performing annual aerial surveys to obtain waterbird population estimates and dynamics. The generated dataset contains between 10,000 and 100,000 records. Migration to the central ESAS database is planned. However, the data is not in the public domain; permission to use data should be asked, and if used, it should be appropriately credited. Financial obstructions for data mobilization are unknown.

Contact person: Ainars Aunins

\subsection{LITHUNANIA}

\subsubsection{LIFE Marine Special Protection Area (SPA) project (LTU)}

From 2006 to 2008, a European LIFE project led by the Baltic Environmental Forum (BEF) Latvia was set up to identify the abundance and distribution of seabirds in territorial water of Lithuania and to designate SPAs. The sampling was carried out by the Nature Research Centre (NRC) and included eight surveys in total in different seasons (primarily winter-spring). These ship-based surveys were performed in the Baltic Sea and generated between 10,000 and 100,000 records. NRC has expressed interest to share their data, and no financial or legal constraints for sharing data were identified. This LIFE project covered Latvia and Estonia as well.

Contact person: Mindaugas Dagys

\section{$5.5 \quad$ RUSSIA}

The Russian Federation is involved in two sampling programmes: the research conducted by the Saint-Petersburg Research Center of Russian Academy of Sciences (SREC RAS) and the sampling campaign led by the Norwegian Institute for Nature Research. The last programme is led by Norway and is discussed there (NINA-NOR).

\subsubsection{Sampling by SREC RAS (RUS)}

In 2018, the Saint-Petersburg Research Center of Russian Academy of Sciences (SREC RAS) conducted aerial surveys connected to Ust-Luga port activities in the Gulf of Finland. Sampling was conducted in spring and autumn 2018, and generated up to 10,000 records. It is unknown if the data will be shared, but no financial or legal constraints for the mobilization were identified.

Contact person: Julia Bublichenko 


\subsection{POLANيND}

\subsubsection{Monitoring of Wintering Sea Birds (POL-MZPM)}

The Museum and Institute of Zoology of the Polish Academy of Sciences (MIIZ), in cooperation with the Polish Society for the Protection of Birds (OTOP), has been coordinating the Monitoring of Wintering Sea Birds programme (MZPM - Monitoring Zimujących Ptaków Morskich) since 2011. MZPM is the only official governmental offshore bird monitoring programme. The aim of the monitoring programme is to determine numbers, distribution and trends of wintering seabird populations in the Baltic Sea. Their sampling campaigns occur on a yearly basis and are ship-based. The dataset includes about 50,000 records (5,000 records yearly) and is managed by the Chief Inspector of Environmental Protection. Currently, the database is compatible with Polish databases and the INSPIRE database. It is currently not possible to transform the database in its current form to the ESAS format. However, the data contained in the database can be transferred on the basis of "data call".

Contact persons: Dominik Marchowski and Włodzimierz Meissner

\subsection{SWEDEN}

\subsubsection{National flight surveys (SWE)}

Since 2004, Lund University has engaged in national flight surveys, occurring on a six-year basis. In between, regional flight surveys are being conducted at the request of count boards. These surveys focus on birds only and take place in the Greater North Sea (OSPAR II) and the Baltic Sea. The database contains between 10,000 and 100,000 records. Migration to the central ESAS v6 database has been planned, although costs for this migration are estimated at $€ 8,000$. No problem is foreseen with respect to the mobilization of publicly funded data. However, Lund University also stores data from surveys financed by private companies. For the latter, permission to share should be asked.

Contact person: Frederik Haas

\subsection{DENMARK}

The questionnaire revealed two sampling programmes: one by the Aarhus University and one by the Dansk Marine Observers ApS (Dansk Bioconsult Aps). Although the latter is known to hold SAS data, they were not able to share the requested information at the present time.

\subsubsection{Programme by Aarhus University (DNK)}

The Aarhus University, Department of Biodiversity, is currently leading the national monitoring of marine birds. Their programme consists of multiple monitoring schemes, with NOVANA as the most permanent one.

Contact person: Ib Krag Petersen 


\subsection{GERMANY}

Germany is currently involved in four running Seabirds at Sea programmes. Three of these programmes combine ship-based surveys with aerial observations in the Greater North Sea (OSPAR II) and the Baltic Sea.

\subsubsection{Monitoring by the Federal Maritime and Hydrographic Agency (DEU-BSH)}

The Federal Maritime and Hydrographic Agency (BSH) stores seabird, migratory bird, marine mammal, benthos and fish data of the Greater North and Baltic Sea from environmental impact assessment (EIA), monitoring from offshore wind farm projects and BSH site investigations. They have been gathering data since 2001. Since 2013, observer-based aerial surveys have been replaced by digital aerial surveys. This information is supplemented with ship-based surveys. The dataset is not yet integrated into the ESAS v5 database, and whether or not the data will be shared in the future is unknown. With respect to seabird monitoring, compliance with the standard investigation framework (StUK) is mandatory for all surveys related to offshore wind energy. Data from EIAs and monitoring data from the German offshore wind industry are privately owned and only aggregated results can be published with the approval of the data owner. Data from BSH offshore site investigations will be publicly available once the tendering process for an offshore wind farm site is completed. No information was provided on potential financial constraints.

Contact person: Gregor van Halem

\subsubsection{The German Marine Biodiversity Monitoring programme (DEU- GMBM)}

The Federal Agency for Nature and Conservation (BfN) is responsible for marine nature conservation in the German Exclusive Economic Zone and has set up the German Marine Biodiversity Monitoring programme. Within this programme, the Research and Technology Centre Westcoast (FTZ) of Kiel University is responsible for the Seabird Monitoring Programme. This programme has been active since 2008 and performs monitoring of seabirds and marine mammals on a yearly basis. Their aerial surveys combine digital with observerbased flights. This dataset is partially integrated into the current ESAS v5 database. No financial constraints were identified and data holders are interested to share their data. The data can be shared in a single ESAS database on the condition that ownership flags are maintained.

Contact persons: Nele Markones, Mirko Hauswirth

\subsubsection{Offshore Seabird Monitoring in the Schleswig-Holstein coastal sea (DEU-OSMS)}

The Offshore Seabird Monitoring in the Schleswig-Holstein coastal sea (North Sea) commissioned by the National Park Authority (NPV-LKN-SH) and carried out by FtZ, Kiel University, has been active since 2004. Since 2010, the programme was scheduled to cover occurrence of Common Scoters and terns, collecting data of all other species as well. Data is collected each winter and summer, with less frequent coverage in other seasons. The dataset is managed by FtZ. No major financial or legal constraints to mobilize the data are expected 
and data holders are most probably interested to share their data, but this should be clarified with the commissioner.

Contact persons: Nele Markones, Stefan Garthe

\subsubsection{The German Seabirds at Sea programme (DEU-SAS)}

The German Seabirds at Sea programme is a long-running programme since 1990 that includes various voluntary or project-based Seabirds at Sea surveys and is coordinated by the Research and Technology Centre Westcoast (FtZ) at Kiel University. The programme focuses on birds and additionally collects data on marine mammals. The dataset is managed by FtZ and part of the data is enclosed in the current ESAS v5 database. No financial constraints were identified and data holders are interested to share their data. The legal sharing conditions differ between the various surveys and should be considered case by case.

Contact persons: Nele Markones, Stefan Garthe

\subsection{NORWAYY}

\subsubsection{The SEAPOP programme (NOR-NINA)}

Norway has one active programme on seabirds and marine mammals: the SEAPOP programme, which started in 2004. In this context, the Norwegian Institute for Nature Research (NINA) is conducting surveys on seabird distribution as a part of a Norwegian/Russian ecosystem survey in the Barents Sea. Next to seabirds, the programme focuses on marine mammals, oceanography, benthos, zooplankton and fish. Sampling occurs each autumn and is ship-based. The dataset holds a large amount of records ( $>1$ million), with currently none of the data being included in the central ESAS v5 database. No financial or legal issues are expected.

Contact person: Per Fauchald

\subsection{THE NETHERLANDS}

The Netherlands currently has three organizations involved in the monitoring of seabirds in the Greater North Sea: Bureau Waardenburg (BuWa, 3 monitoring programmes), the Royal Netherlands Institute for Sea Research (1 monitoring programme) and Wageningen Marine Research (1 monitoring programme). All these programmes are currently ongoing and focus on both seabirds and marine mammals.

\subsubsection{Aerial surveys BuWa (NLD-BuWa-AIR)}

Since 2004, Bureau Waardenburg has been involved in various short- and long term aerial survey programmes. For some programmes, sampling occurs every two weeks for a short time period, for others, sampling occurs monthly. Examples of the studies were PMR-NCV where during the summer season between 2009 and 2019 aerial surveys were conducted twice a month to study seabirds in the Voordelta SPA. Another example are some dedicated aerial surveys of Great Crested Grebe and Little Gull in the Dutch coastal zone and Lake IJsselmeer in 2012 and 2014 respectively. All data are stored in the same format. The database holds up to one million records. None of these records have been included in the ESAS database, although BuWa is interested to share their data. Nevertheless, costs for data mobilization are estimated 
at $€ 2,500$. Additionally, some of the aerial survey data are owned by clients for which permission needs to be obtained.

Contact person: Ruben Fijn

\subsubsection{Ship-based surveys BuWa (NLD-BuWa-SHIP)}

Since 2004, Bureau Waardenburg has been conducting a few ship-based surveys generating between 10,000 to 100,000 records. Examples of such studies were PMR-NCV where between 2004 and 2006 ship-based surveys were conducted to study seabirds in the Voordelta SPA. Another example are some dedicated ship-surveys of Sandwich Terns in the Dutch coastal zone 2020. Data mobilization should not be a problem as Rijkswaterstaat has ownership of the data, though the mobilization might cost up to $€ 2,500$.

Contact person: Ruben Fijn

\subsubsection{Monitoring Waterstaatkundige Toestand des Lands (MWTL) programme (NL-MWTL)}

The MWTL Seabird programme is performing bi-monthly aerial surveys of seabirds and marine mammals on the Dutch Continental Shelf (NCP), with increased effort in the coastal zone and in designated Natura 2000-SPAs. These data are owned by Rijkswaterstaat and managed on their behalf by Sovon bird research. The programme runs since 1984 in different forms. Some major changes were made to the methodology and design in 1991 and 2014. They have a large database (up to one million records), for which the mobilization to ESAS has recently been carried out. Data sharing (particularly in view of inclusion in the ICES database) is strongly supported, but some legal issues will have to be solved.

Contact person: Ruben Fijn, Mervyn Roos, Menno Hornman

\subsubsection{Programme by Royal Netherlands Institute for Sea Research (NLD-NIOZ)}

Since 1985, the Royal Netherlands Institute for Sea Research is involved in year round, shipbased seabirds at sea studies in the Arctic waters (OSPAR Region I), Greater North Sea (OSPAR Region II), Bay of Biscay and Iberian Coast (OSPAR Region IV), Wider Atlantic (OSPAR Region V) and tropics. Next to the systematic screening of ecology and species interactions, they record interactions with fisheries. They manage over 1 million of records, which are partially included in the central ESAS database. Database updates are foreseen, as soon as ESAS is planning an update. No financial constraints are foreseen. Legal constraints include that the commercial use of the data has to be budgeted.

Contact person: Kees Camphuysen

\subsubsection{Programme by Wageningen Marine Research (NLD-WUR)}

Wageningen Marine Research is currently leading a long-running (since 1980) ship-based sampling programme covering a large geographical area (OSPAR I, II, III and IV regions). The database hosts a large number of records, which are partially included in the current ESAS database $(n=477,552)$. No financial constraints have been identified. No legal constraints are identified for data owned by WUR. However, their database also includes data from the Dutch Seabird Group, for which permission needs to be obtained. 


\subsection{BELGIUMM}

Belgium currently has two active monitoring programmes. They both focus on seabirds and marine mammals in the Belgian part of the North Sea (OSPAR II region).

\subsubsection{Monitoring by the INBO (BEL-INBO)}

Belgium has been performing ship-based monthly surveys to monitor the number and distribution of seabirds and marine mammals, in order to provide input in assessments regarding anthropogenic impacts or input into the Marine Strategy Framework and Bird Directives. These surveys have been carried out by the Research Institute for Nature and Forest (INBO) since 1992 and are still ongoing, however the frequency of recording was lower during 1992-2000. They host a SAS dataset containing between 32,400 records, which is partially integrated in the current ESAS v5 database. Although no financial constraints are mentioned and there's an interest for sharing the data, the data collected within wind farm monitoring surveys (commissioned by the Scientific Service Management Unit of the Mathematical Model of the North Sea (MUMM)) cannot be used nor be distributed without written permission of MUMM.

Contact person: Eric Stienen, Nicolas Vanermen

\subsubsection{Monitoring by the MUMM (BEL-RBINS)}

Since 2008, the Scientific Science Management Unit of the Mathematical Model of the North Sea (MUMM) has been performing aerial surveys of birds and marine mammals. Marine mammals are identified on a visual basis and photographs are taken to further analysis of tracks. These surveys have generated up to 10,000 records. Whether or not MUMM is willing to share their data is unknown. No financial constraints were identified, but data can only be shared with a contribution to the data collector.

Contact person: Jan Haelters

\subsection{GREAT BRITAIN}

The United Kingdom is currently engaged in four monitoring surveys and projects in the Greater North Sea (OSPAR II region), all currently active and each focussing on both birds and marine mammals and often with a specific focus on wind farms.

\subsubsection{HiDef Aerial Surveying Limited (GBR-HIDEF)}

HiDef Aerial Surveying Limited is involved in multiple post consent and Special Protection Area (SPA) monitoring projects (https://www.hidefsurveying.co.uk/case-studies/) in the Greater North Sea (OSPAR II) and the Celtic Seas (OSPAR Region III). The general goal of these aerial surveys is to measure the effects and impacts of offshore windfarms on seabird distribution and to monitor changes in numbers and distribution of seabirds in marine SPAs. These projects are commissioned by wind farm developers and the UK statutory bodies such as the Joint Nature Conservation Centre (JNCC), Marine Scotland Science (MSS), Natural England (NE), Scottish Natural Heritage and the Marine Institute in Ireland (MI). HiDef started its first commercial flights in 2009. Their database hosts more than one million records which are currently not integrated in the ESAS database, but integration is planned. Upon migration of 
the data, line and strip transect data would have to be segmented to ensure compatibility. The sharing conditions would need to be negotiated with the data owners on a case-by-case basis. Commercial clients are usually reluctant to share the data, while governmental and nongovernmental clients are almost always in favour of sharing.

Contact person: Andy Webb

\subsubsection{British Seabirds at Sea programme (GBR-JNCC)}

The Joint Nature Conservation Centre is currently leading the British Seabirds at Sea programme. This programme has been active since 1980. Observations are made by ship and plane and focus mainly on seabirds and marine mammals in UK waters. The JNCC data, including more than one million records, is currently integrated in the central ESAS v5 database. No financial or legal constraints for mobilizing the data were identified.

Contact person: Mark Lewis

\subsubsection{Sheringham Shoal Offshore Wind Farm programme (GBR-OWF)}

Between 2004 and 2016, ECON (Ecological Consultancy) acted as the lead ornithological consultant in the Norwegian SAS programme at the Sheringham Shoal Offshore Wind Farm between 2004 and 2016. Their monitoring programme included birds and marine mammals in the Greater North Sea (OSPAR Region II). They performed ship-based surveys on a year round basis, with monthly intervals and greater survey intensity in breeding seasons. Their database hosts between 10,000 and 100,000 records. None of these records are currently included in the ESAS database. It is uncertain whether financial or legal issues would constrain data mobilization.

Contact person: Richard Berridge

\subsubsection{Seagreen Firth of Forth Zone programme (GBR-SFF)}

Since 2009, Seagreen Wind Energy has been leading the Firth of Forth Zone offshore wind farm development programme to monitor seabirds. Between 2009 and 2011, surveys were conducted on a monthly basis. Since then, surveys were targeted at the breeding season. About 100,000 to 1 million records have been collected since 2009, but none of those have been included in the central ESAS database up to now. It remains unclear whether or not Seagreen Wind Energy would be willing to share their data, or whether financial or legal constraints would prevent the mobilization of the dataset.

Contact person: Richard Berridge

\subsection{IRELAND}

The questionnaire identified three monitoring programmes, but one organisation, Natural Power Ireland, was not allowed to share the requested information at the present time. Natural Power usually undertakes SAS surveys on behalf of renewable energy developers to produce baseline datasets for impact assessments, and therefore datasets and associated metadata becoming available would usually correspond with the submission of the Environmental Impact Assessment (EIA) Report. 


\subsubsection{Monitoring programme led by National Parks and Wildlife Service (IRL-NPWS-1 and IRL-NPWS-2)}

The National Parks and Wildlife Service leads multiple pelagic fisheries surveys that include seabird and marine mammals records in the Celtic Seas (OSPAR Region III, IRL-NPWS-1). These ship-based surveys started in 2018 and are ongoing. The data (> 10,000 records) are intended to be used in the central ESAS database (older data may have been uploaded already). Although the data are collected by agencies with an open-access policy, the publication of some datasets may be under moratorium.

Contact person: Graham Johnston

Additionally, From 2016 onwards, the National Park and Wildlife Service is working together with the Marine Institute and the Department of Communications, Climate Action and Environment in Ireland on multiple surveys (e.g. ObSERVE) to collect seabirds at sea data in a standardized way (IRL-NPWS-2. Their ship-based and aerial surveys focus on seabirds only in the Irish Exclusive Economic Zone (EEZ). Currently, the ObSERVE programme has stopped, but boat-based surveys are to start again in 2021 and digital aerial surveys are still ongoing. Although there's an interest for sharing their data, the financial and legal implications of the data mobilization need consideration.

Contact person: David Tierney

\subsection{FRANCE}

\subsubsection{The MEGASCOPE programme (FRA)}

The MEGASCOPE programme, currently funded by the French Office of Biodiversity (OFB), is led by Observatoire PELAGIS and has been active since 2004 and focuses on birds, marine mammals, turtles and large fish in the Greater North Sea (OSPAR II), the Celtic Seas (OSPAR Region III) and the Bay of Biscay and the Iberian Coast (OSPAR Region IV). The programme includes a sighting protocol dedicated for marine megafauna for four halieutics surveys PELGAS, IBTS, CGFS, EVHOE (Ifremer's fisheries monitoring). These surveys are annual and concern a sampling for two seasons in the Atlantic (springtime and fall) and two in the English Channel (winter and fall). They are conducted for every monitoring cycle for the Marine Strategy FrameWork Directive. Their database hosts between 10,000 and 100,000 records. The data holders have expressed interest in sharing their data with the central ESAS database and see no financial constraints for doing so. Data can be shared on the condition that the source is cited or co-authorship is considered in case of publication.

Contact person: Ghislain Doremus

\subsection{SPAIN}

We identified five active monitoring programmes in the Bay of Biscay and Iberian Coast (OSPAR IV). All programmes are ship-based, focus on both seabirds and marine mammals, and occur on a yearly basis.

\subsubsection{Seabird and cetacean monitoring programmes (ESP-AV3)}

The Spanish Institute of Oceanography (IEO) has been involved in the seabird and cetacean monitoring programmes under the framework of the Marine Strategy Framework Directive 
since 2007. The programme generated between 10,000 and 100,000 records. These records are not included in the ESAS v5 database. It is unsure whether legal or financial constraints will obstruct future migration.

Contact person: Camilo Saavedra

\subsubsection{The JUVENA and BIOMAN programmes (ESP-JUV and ESP-BIO)}

The JUVENA (active since 2013) and BIOMAN (active since 2016) programmes are both led by AZTI (Ciencia y tecnología marina y alimentaria). For both programmes, the sampling strategy is designed to monitor European anchovy and other small pelagic fish over both Spanish and French continental shelf and slope waters. Each programme generated up to 10,000 records. Mobilization to a central ESAS database might be complicated from both a legal and financial point of view, though the specific conditions are unclear and should be analyzed.

Contact person: Maite Louzao

\subsubsection{The PELACUS programme (ESP-PEL)}

The PELACUS programme led by the Spanish Institute of Oceanography (IEO) has been active since 2007 and focuses mainly on Spanish shelf waters in the North and North-West Iberian Coast. The programme generated between 10,000 and 100,000 records. These records are not included in the ESAS v5 database. It is unsure whether legal or financial constraints will obstruct future migration.

Contact person: Camilo Saavedra

\subsubsection{The ECOCADIZ programme (ESP-UCA)}

The University of Cádiz, together with the Spanish Institute of Oceanography, is currently (since 2006) leading the ECOCADIZ programme. The generated database includes up to 10,000 records, with migration to the central ESAS v6 database planned. Whether or not extra costs are associated with the migration is unknown. Sharing of the data is only possible after the publication of the research in the context of a PhD.

Contact person: Andrés Delacruz

\subsection{PORTUيGAL}

\subsubsection{Portuguese Seabirds at Sea programme (PRT)}

Since 2005, the Portuguese Society for the Study of Birds (SPEA) has been collecting data on seabirds and other megafauna (marine mammals and reptiles) at sea using the ESAS methodology. The data is collected under different frameworks in the aim of specific projects. Sampling is ship-based and occurs on a monthly basis. The database includes 100,000 to 1 million species occurrence records from the Portuguese Exclusive Economic Zone, stored in Paradox. Part of these data has been enclosed in the central ESAS database. No financial or legal issues for the mobilization were identified.

Contact person: Nuno Oliveira 


\subsection{GREECEE}

Greece is currently involved in two active monitoring programmes: the Hellenic Seabird Project and the European Marine Strategy Framework Directive (MSFD) for Greece, funded through three LIFE projects. All programmes, except for the MSFD programme, were led by the Hellenic Ornithological Society and BirdLife Greece. The MSFD programme was led by the Hellenic Center for Marine Research. All programmes took place in the East Mediterranean Sea and were ship-based.

Contact person (for all programmes): Dana Portolou

\subsubsection{Hellenic Seabird Project (GRC-HSP)}

The aim of the HSP project is to gather reliable information on the population status and conservation priorities of Greek seabirds in order to establish the National Marine Important Bird and Biodiversity Area (IBA) Network, to produce National Species Action Plans and to support their active conservation. The project started in 2013 and is still ongoing. The project generated up to 10,000 records, none of which have been included in the ESAS v5 database. There is an interest in sharing data and financial constraints were identified. The legal framework for data mobilization should be clarified.

\subsubsection{Past LIFE projects (GRC-LIFE96, GRC-LIFE03, GRC-LIFE07)}

We identified three past LIFE projects that generated SAS data:

LIFE project "Larus audouinii - Conservation actions for Larus audouinii in Greece" (GRCLIFE96) (1992-2001)

LIFE project: “Conservation measures for Falco eleonorae in Greece (GRC-LIFE03)” (2004-2006)

LIFE project "Concrete conservation measures for the Mediterranean Shag and Audouin's Gull in Greece, including the inventory of relevant marine IBAs" (GRC-LIFE07) (2009-2012)

Each project generated up to 10,000 records on these specific species. It is not sure whether these records are included in the current ESAS database, but there is an interest to share, although the legal aspect of this mobilization should be clarified. No financial constraints were identified.

\subsubsection{EU MSFD programme for Greece (GRC-MSFD)}

The European Marine Strategy Framework Directive programme for Greece was set up to monitor the good environmental status of marine waters (D1C1, D1C2 and D1C3 criteria of the MSFD). The programme was led by the Hellenic Center for Marine Research (HCMR) and started in 2020. The programme generated up to 10,000 records so far. None of the records are included in the ESAS v5 database but the respondents are interested in sharing their data. However, both legal and financial constraints could complicate the migration. Costs are estimated at $€ 5,000$, no legal specifications were given.

\subsection{MALTA (MLT)}

In 2020, Malta started the LIFE project ("LIFE PanPuffinus!: Improving the conservation status of endemic Balearic and Yelkouan shearwaters by ensuring safe land and sea"). The project's 
overall aim is to improve the conservation status of two endangered Puffinus species across the Mediterranean Sea and the Atlantic coast of Portugal. At this point, up to 10,000 records were gathered, none of which are included in the ESAS database yet. The respondents expressed their willingness to share their data but the mobilization would cost around $€ 5,000$. The legal constraints for mobilization are unknown.

Contact person: Dana Portolou 


\section{References}

RStudio Team (2020). RStudio: Integrated Development for R. RStudio, PBC, Boston, MA URL http://www.rstudio.com/ 